\title{
Calculating the Surface Area of the Water in A Rolling Cylinder and Visualization as two and three Dimensional by Means of Geogebra
}

\author{
Muharrem Aktumen \\ Assist. Prof. Dr. \\ Ahi Evran University Faculty of \\ Education, \\ Department of Elementary \\ Mathematics. Turkey
}

\author{
Serdal Baltaci \\ Instructor \\ Ahi Evran University, Çiçekdagı \\ Vocational School. Turkey
}

\author{
Avni Yildiz \\ Research Assistant. \\ Ahi Evran University Faculty of \\ Education, \\ Department of Elementary \\ Mathematics. Turkey
}

\begin{abstract}
A real life problem was created in this study and ellipse equations and integral concept were used in the solution of this problem. As a real life problem, the change in the surface area of the water in a cylinder half of which was full of water and situated vertically was examined in a process in which it was tilted until it became parallel to the floor. In the study, piecewise function which gave the surface area of the water for the angle that the floor and the cylinder built was constructed. This process was visualized as two and three dimensional using GeoGebra which is a dynamic mathematics software program. As this problem situation overlaps with the principles of Realistic Mathematics Education approaches, it is believed that it will guide the teachers in classroom activities.
\end{abstract}

Keywords: Cylinder; Realistic Mathematics Education; GeoGebra; Three Dimensional Modeling.

\section{INTRODUCTION}

Although the knowledge produced and the issues studied by the mathematicians are seen as unnecessary by some, it has been observed that this produced knowledge can be used centuries later [1]. For example, the integral equations on which Hilbert had worked were used in quantum physics almost 80 years later. There was a 100 years of period between Riemann's discovery of non-Euclidian geometry and its use in space calculations [2]. Ellipses, parabola and hyperbola curves which ancient Greeks called as conics are among the studies which were seen as unnecessary by many people but quite beneficial for human beings later [1].

When a cone with a circle base is crossed with the plane, different shapes are formed which changes according to the slope of the plane (Figure 1). These shapes are called as conics.
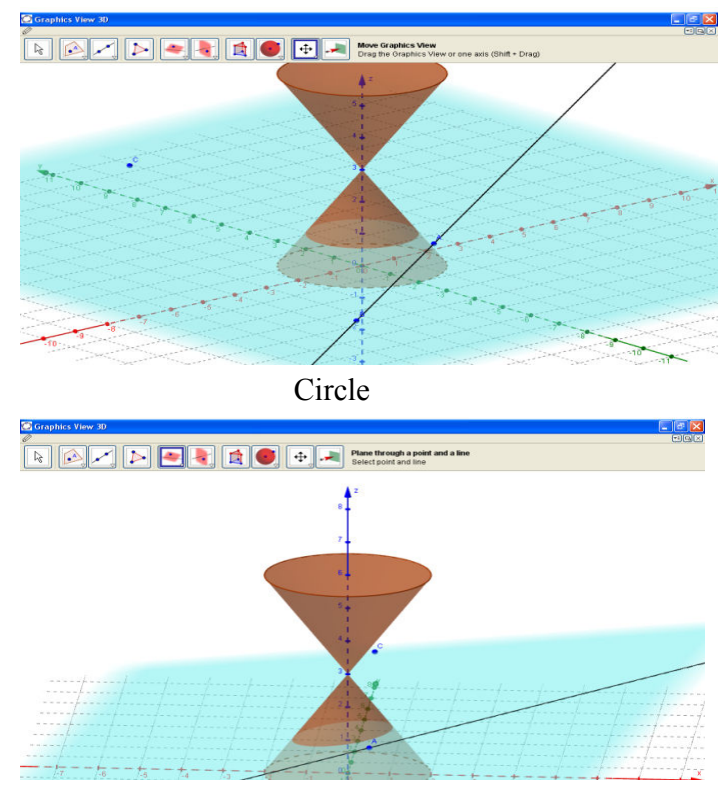

Ellipse

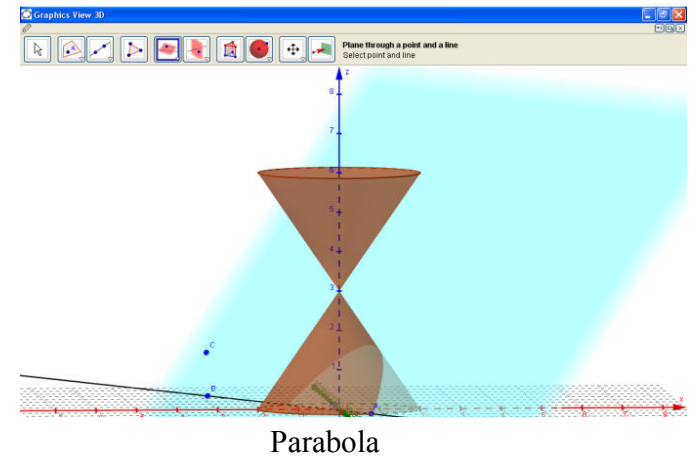

Note: A part of this study was presented in the Ninth Mathematics Symposium as a verbal statement on 20 October 2010 and a part of project (Scientific Research Project Code: SBA-09-01) supported by Ahi Evran University. 


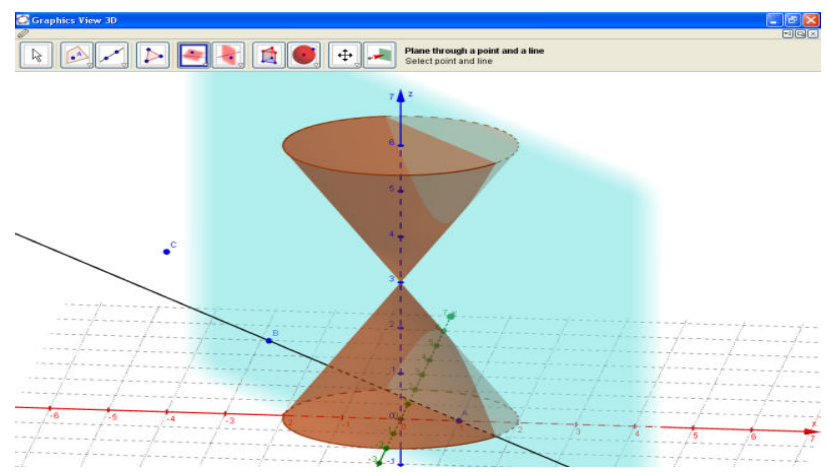

Hyperbola

FIG. 1. The presentation of conics with GeoGebra

There are many cases in which the conic surfaces are used in engineering designs and mould industry. The most important feature of conic section or areas is that the sections of these surfaces change throughout their heights [3]. Ellipse which is one of the conic sections can frequently be seen in our daily life. Simply, a circle whose plane is not vertical for our view direction is seen as an ellipse to us. For example, the top of a cylindrical glass is seen as ellipse when it is looked from a certain angle. The projecting of a circle on a surface is also an ellipse. The surface of the water in a glass half of which is full of water and hold as leaned (not only the view from the side but also itself) is an ellipse. All of these mean that the section which is obtained when a cylinder is crossed with a plane unparallel to its base is called ellipse. The slices of salami that were beveled are ellipses. This kind of examples can be considered within the context of Realistic Mathematics Education which was developed by Hans Freudenthal. Realistic mathematics education involves a complete reversal of the teaching/ learning process [4]. Two fundamental concepts in realistic mathematic education approach are horizontal and vertical mathematization. In horizontal mathematization, students come with the tools that can help to organize and solve the problems placed and exist in real life. On the other hand, vertical mathematization is a reorganizing method in mathematical system [5]. Dynamic geometry software programs are important tools in fulfilling these two concepts. GeoGebra can be considered as a dynamic geometry software program as it studies on points, line segments, lines, conic sections and similar mathematical concepts; however, it can also be considered as computer algebra systems as it allows the direct access of the points, coordinates, equations and functions, the algebraic identification and dynamically modification. It allows fast transitions among the representations by accomplishing the transfer of mathematical symbols, graphics and values in a dynamic process with its algebra, drawing board and calculation chart window views; and it differentiates from other dynamic geometry software programs and computer algebra systems with these features [6]. It exists as an important value in making connections between geometry and algebra in school curricula with its potentials and capabilities in mathematics education [7]. In this study, a problem situation which can be used within the context of Realistic Mathematics Education approach was formed.

\subsection{Problem Statement:}

What is the piecewise function that is connected to $\alpha$ which gives the area of water surface in a cylinder half of which was filled with water, the height of which is $h$, the radius is $r$ and the angel that build with the floor is $\alpha$ ?

\section{METHOD}

In this study, the change in the surface area of the water in a cylinder half of which was full of water and situated vertically was examined in a process in which it was tilted until it became parallel to the floor. In the study, piecewise function which gave the surface area of the water for the angle that the floor and the cylinder built was constructed. This process was visualized using the GeoGebra 5.0 Beta Release version.

\section{FINDINGS}

Two situations are available for the solution of this problem.

\section{$3.11^{\text {st }}$ Situation:}

The place of the cylinder for $\arctan \left(\frac{2 \mathrm{r}}{h}\right) \leq \alpha \leq \frac{\pi}{2}$ interval is modeled in Figure 2 and Figure 3.

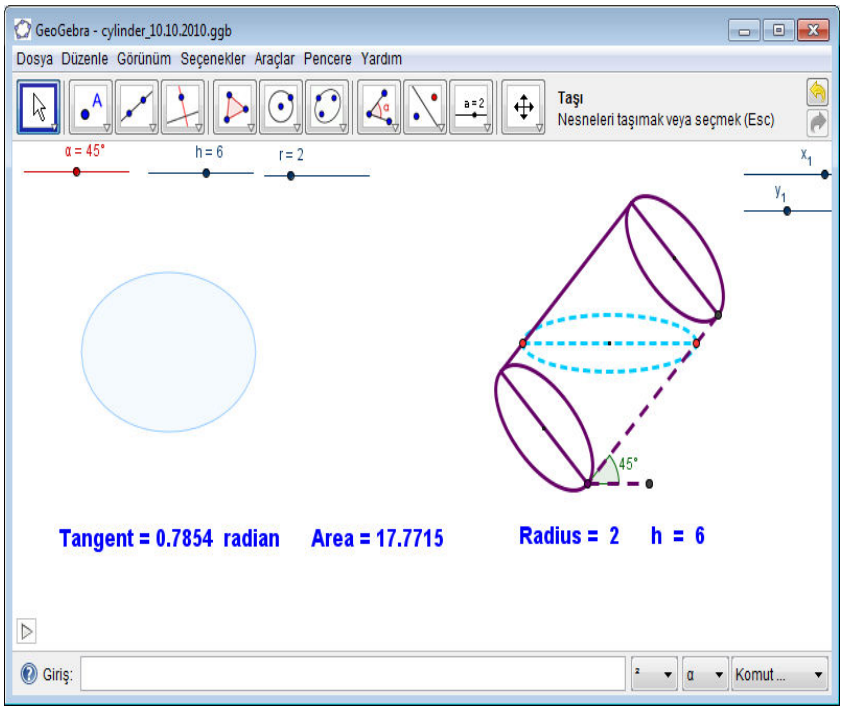

FIG.2. Two- dimensional visualization of the water surface and the cylinder with GeoGebra 


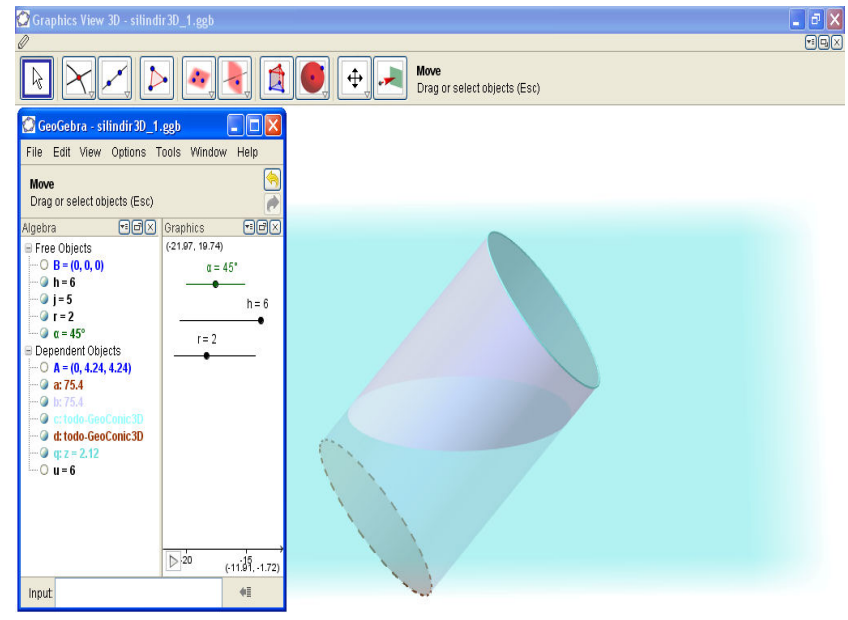

FIG. 3. Three- dimensional visualization of the water surface and the cylinder with GeoGebra

The case in which the length of the major axis of the ellipse that the water surface formed was the highest was visualized in Figure 4. Using this visualization, $\alpha$ angle was determined in terms of $\mathrm{r}$ and $\mathrm{h}$; and the major axis length of the ellipse was determined in terms of $r$.
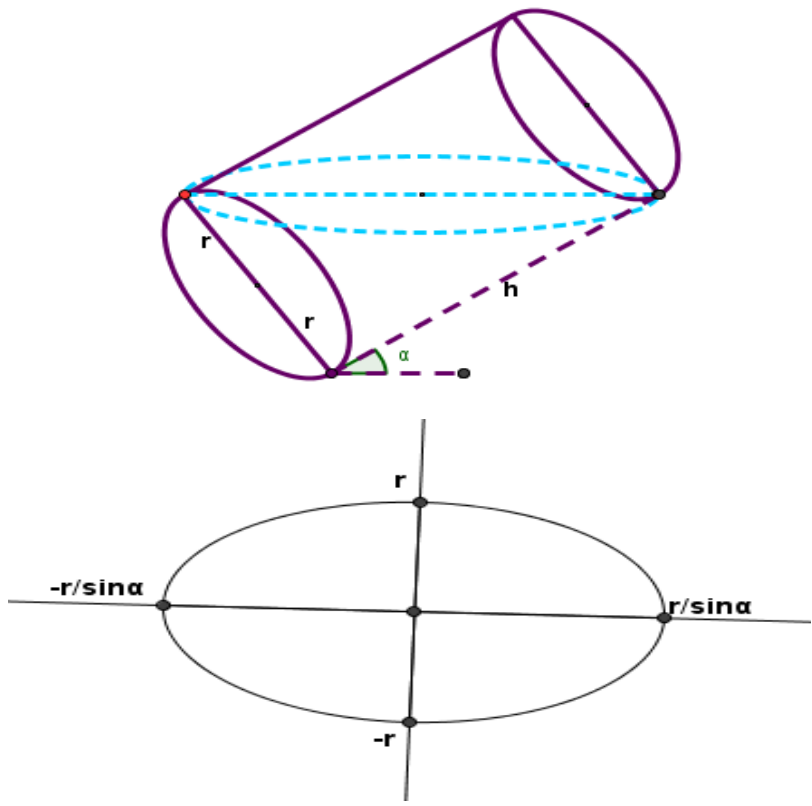

FIG. 4. The visualization of the cylinder and the surface of the water for $\alpha=\arctan \left(\frac{2 \mathrm{r}}{h}\right)$

The area of water surface in a cylinder half of which was filled with water, the height of which is $h$, the radius is $r$ and the angel that build with the floor is $\alpha$ was calculated as below.
In $2 \int_{\frac{-r}{\sin \alpha}}^{\frac{r}{\sin \alpha}} \sqrt{r^{2}-x^{2} \sin ^{2} \alpha} d x \quad$ integral, when the statement in the square root is multiplied with and divided by $\sin ^{2}(\alpha)$

$2 \sin \alpha \int_{\frac{-r}{\sin \alpha}}^{\frac{r}{\sin \alpha}} \sqrt{\frac{r^{2}}{\sin ^{2} \alpha}-x^{2}} d x \quad$ integral is obtained.

When the variable is changed, it becomes $d x=\frac{r}{\sin \alpha} \cos \beta d \beta$. When the limits are determined and the statements are placed,

$2 \sin \alpha \int_{-\frac{\pi}{2}}^{\frac{\pi}{2}} \sqrt{\frac{r^{2}}{\sin ^{2} \alpha}-\frac{r^{2}}{\sin ^{2} \alpha} \sin ^{2} \beta} \frac{r}{\sin \alpha} \cos \beta d \beta \quad$ is obtained.

Here,

$2 \sin \alpha \int_{-\frac{\pi}{2}}^{\frac{\pi}{2}} \sqrt{\frac{r^{2}}{\sin ^{2} \alpha}\left(1-\sin ^{2} \beta\right)} \frac{r}{\sin \alpha} \cos \beta d \beta$

$=2 \sin \alpha \int_{-\frac{\pi}{2}}^{\frac{\pi}{2}} \sqrt{1-\sin ^{2} \beta} \frac{r}{\sin \alpha} \frac{r}{\sin \alpha} \cos \beta d \beta$

$=2 \frac{r^{2}}{\sin \alpha} \int_{-\frac{\pi}{2}}^{\frac{\pi}{2}} \sqrt{1-\sin ^{2} \beta} \cos \beta d \beta$

$=2 \frac{r^{2}}{\sin \alpha} \int_{-\frac{\pi}{2}}^{\frac{\pi}{2}} \sqrt{\cos ^{2} \beta} \cos \beta d \beta$

$=2 \frac{r^{2}}{\sin \alpha} \int_{-\frac{\pi}{2}}^{\frac{\pi}{2}}|\cos \beta| \cos \beta d \beta$

$=2 \frac{r^{2}}{\sin \alpha} \int_{-\frac{\pi}{2}}^{0} \cos ^{2} \beta d \beta+2 \frac{r^{2}}{\sin \alpha} \int_{0}^{\frac{\pi}{2}} \cos ^{2} \beta d \beta$ integral is obtained.

using $\cos ^{2} \beta=\frac{\cos 2 \beta+1}{2}$ correlation. 


$$
\begin{aligned}
& 2 \frac{r^{2}}{\sin \alpha} \int_{-\frac{\pi}{2}}^{0} \frac{\cos 2 \beta+1}{2} d \beta+2 \frac{r^{2}}{\sin \alpha} \int_{0}^{\frac{\pi}{2}} \frac{\cos 2 \beta+1}{2} d \beta \\
& =\left.\frac{r^{2}}{\sin \alpha}\left(\frac{\sin 2 \beta}{2}+\beta\right)\right|_{-\frac{\pi}{2}} ^{0}+\left.\frac{r^{2}}{\sin \alpha}\left(\frac{\sin 2 \beta}{2}+\beta\right)\right|_{0} ^{\frac{\pi}{2}} \\
& =\frac{r^{2} \pi}{2 \sin \alpha}+\frac{r^{2} \pi}{2 \sin \alpha} \\
& =\frac{\pi r^{2}}{\sin \alpha} \text { is found. }
\end{aligned}
$$

\section{$3.22^{\text {nd }}$ Situation:}

3.2.1. The place of the cylinder for $0<\alpha<\arctan \left(\frac{2 \mathrm{r}}{h}\right)$ interval was modeled in Figure 5 and Figure 6.

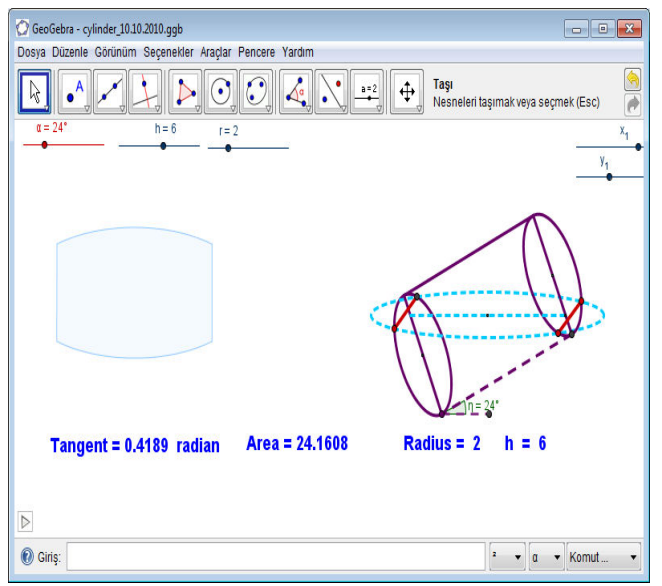

FIG. 5. Two- dimensional visualization of the water surface and the cylinder with GeoGebra

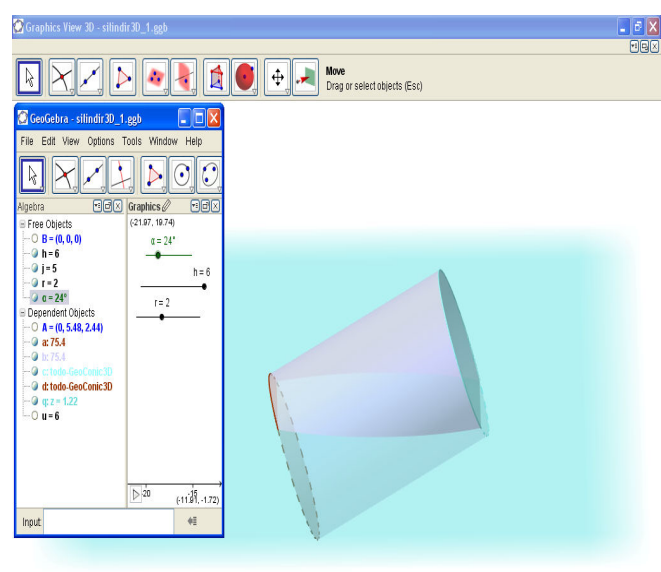

FIG. 6. Three- dimensional visualization of the water surface and the cylinder with GeoGebra
In order to find the area of the shape that water surface formed in $0<\alpha<\arctan \left(\frac{2 \mathrm{r}}{h}\right)$ interval, $\mathrm{t}$ length was determined in terms of $h$ and $\alpha$.

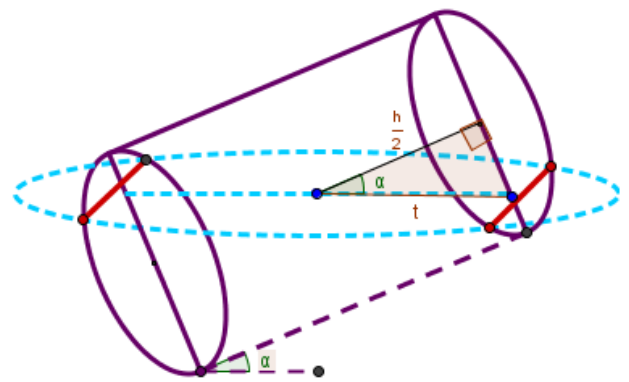

FIG. 7. The process of the second situation limits determination

While forming the integral that gave the surface area of the water in the second situation, the function formed in the first situation was used and the limits were reorganized. When the integral was calculated;

$$
\begin{aligned}
& 2 \int_{-h}^{\frac{h}{2 \cos (\alpha)}} \sqrt{r^{2}-x^{2} \sin ^{2}(\alpha)} d x \\
= & \left.\frac{r^{2}}{\sin \alpha}\left(\frac{\sin 2 \beta}{2}+\beta\right)\right|_{\arcsin \left(-\frac{h \sin \alpha}{2 r \cos \alpha}\right)} ^{0}+\left.\frac{r^{2}}{\sin \alpha}\left(\frac{\sin 2 \beta}{2}+\beta\right)\right|_{0} ^{\arcsin \left(\frac{h \sin \alpha}{2 r \cos \alpha}\right)} \\
= & \frac{r^{2}}{\sin \alpha}\left(\frac{\sin 2\left(\arcsin \left(-\frac{h \sin \alpha}{2 r \cos \alpha}\right)\right)}{2}+\arcsin \left(-\frac{h \sin \alpha}{2 r \cos \alpha}\right)+\frac{\sin 2\left(\arcsin \left(\frac{h \sin \alpha}{2 r \cos \alpha}\right)\right)}{2}+\arcsin \left(\frac{h \sin \alpha}{2 r \cos \alpha}\right)\right)
\end{aligned}
$$

The following statement can be reached.

3.2.2. When $\alpha=0$, the cylinder was in a horizontal position and the water inside it was in rectangle shape (Figure 8). The area of this rectangle was seen to be $2 \mathrm{rh}$.

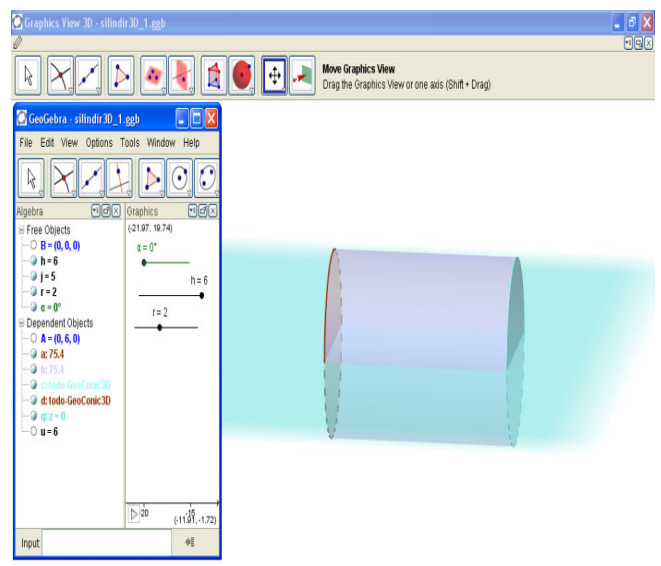

FIG. 8. Three- dimensional visualization in $\alpha=0$ with GeoGebra 


\section{CONCLUSION}

The piecewise function obtained under these conditions is as follows;

$$
\begin{aligned}
& \text { If } f:\left[0, \frac{\pi}{2}\right] \rightarrow \square \\
& \qquad f(x)=\left\{\begin{array}{l}
\frac{\pi r^{2}}{\sin \alpha} \\
\frac{r^{2}}{\sin \alpha}\left(\frac{\sin 2\left(\arcsin \left(-\frac{h \sin \alpha}{2 r \cos \alpha}\right)\right)}{2}+\arcsin \left(-\frac{h \sin \alpha}{2 r \cos \alpha}\right)+\frac{\sin 2\left(\arcsin \left(\frac{h \sin \alpha}{2 r \cos \alpha}\right)\right)}{2}+\arcsin \left(\frac{h \sin \alpha}{2 r \cos \alpha}\right)\right) ; 0<\alpha<\arctan \left(\frac{2 \mathrm{r}}{h}\right) \leq \alpha \leq \frac{\pi}{2} \\
2 r h
\end{array}\right) ; \alpha=0
\end{aligned}
$$

Traditional mathematics education is sometimes referred to as mechanistic mathematics education [8]. But Freudenthal's view that mathematics must be connected to reality, stay close to children, and be relevant to society in order to be of human value [9]. On the other hand, according to Freudenthal, mathematics can best be learned by doing and mathematizing is the core goal of mathematics education [10]. Mathematizing in Realistic Mathematics Education is seen as important to mathematics education because it is the major activity of mathematicians and familiarizes students with the mathematical approach to everyday settings and it relates to the process of reinvention in which students formalize their informal understandings and intuitions [11].

Computer-aided presentation of modeling and realist mathematics education is not very common. Therefore, models similar to the activity presented as a problem situation in this paper should be increased in number. In this way, as Zbiek and Conner point out, modeling contributes to understand the fore known mathematical concepts thoroughly by demonstrating the applicability of mathematical thoughts to real life, to learn new mathematical concepts, to establish inter disciplinary relations and to both conceptual and operational development of the students studying in modeling processes [12]. On the other hand, Van Drieland Verloop indicate that most teachers think models as simplified or schematic re presentations of the realities [13]. Yet, according to Berry and Houston, one can develop his modeling skill by solving real life problems and trying to formulate the models correctly [14].

\section{REFERENCES}

[1] Batson, H. 2005. Konikler en doğal halleriyle, Matematik Dünyası,14-18. http://www.matematikdunyasi.org/arsiv/PDF/05_2_14_18_ KONIKLERENDOGAL.pdf

[2] Baki, A. 2008. Kuramdan uygulamaya matematik eğitimi. (Genişletilmiş Dördüncü Baskı), Harf Eğitim Yayıncılığı, Ankara.

[3] Ozel, C. \& Huseyınoglu, M. 2009. Çan şekilli bir yüzeyin cnc freze tezgahinda imalati için cam kodlarinin matlab programlama ile oluşturulması, Fırat Üniversitesi Mühendislik Bilimleri Dergisi, 21(2), 141-149.

[4] Treffers, A. \& Beishuizen, M. 1999. Realistic mathematics education in the Netherlands, in Thompson, I. (ed) Issues in teaching numeracy primnrv schools, Buckingham: Open University Press.
[5] Demirdogen, N. 2007. Gerçekçi matematik eğitim yöntemlerinin ilköğretim 6. sinıflarda kesir kavramının ögretimine etkisi, Gazi Üniversitesi, Eğitim Bilimleri Enstitüsü, İlköğretim Matematik Öğretmenliği Anabilim Dalı, Yayınlanmamış Yüksek Lisans Tezi, Ankara.

[6] Aktumen, M., Horzum, T., Yildiz, A. \& Ceylan T. 2010. Bir dinamik matematik yazilimi: Geogebra ve ilkögretim 68. sinif matematik dersleri için örnek etkinlikler, Isbn:978605-125-189-9.

Http://Ankarageogebra.Org/Cms/Aktumen/Ekitap/.

[7] Hohenwarter, M \& Jones, K. 2007. Ways of linking geometry and algebra: the case of GeoGebra, Proceedings of British Society for Research into Learning Mathematics, 27,3, November 2007.

[8] Van den Heuvel-Panhuizen, M. 2001. November. Realistic mathematics education as work in progress. Paper presented at the meeting of The Netherlands and Taiwan Conference on Mathematics Education, Taipei, Taiwan.

[9] Freudenthal, H. 1977. Adress to the first conference of I.G.P.M.E, at Utrecht 29 August 1977, in Educational Studies in Mathematics, 9:1.

[10] Freudenthal, H.: 1973. Mathematics as an Educational Task, Riedel Publishing Company, Dordrecht, The Netherlands.

[11] Gravemeijer, K., Cobb, P., Bowers, J. \& Whitnack, J. 2000. Symbolizing, modeling and instructional design. In $\mathrm{P}$. Cobb, E. Yackel, \& K. McClain (Eds.), Symbolizing and communicating in mathematics classrooms (pp. 225-273). Mahwah, NJ: Erlbaum.

[12] Zbiek, R. M., \& Conner, A. 2006. Beyond motivation: Exploring mathematical modeling as a context for deepening students' understandings of curricular mathematics. Educational Studies in Mathematics, 63(1), 89-112.

[13] Van Driel, H. J., \& Verloop, N. 1999. Teachers' knowledge of models and modelling in science, International Journal of Science Education, 21 (11), 11411153.

[14] Berry, J., \& Houston, K. 1995. Mathematical modelling. Bristol: J. W. Arrowsmith Ltd. 